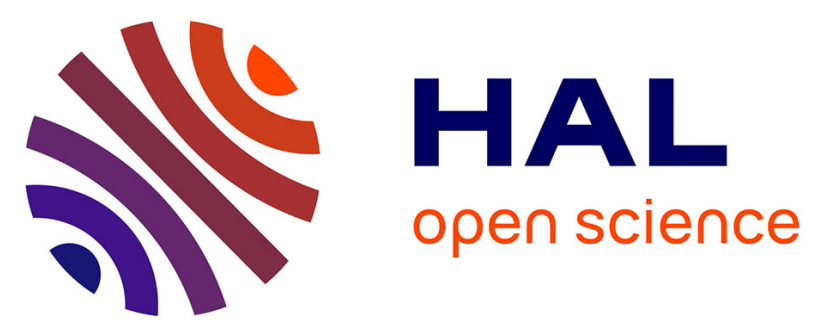

\title{
Testosterone secretion in elite adolescent swimmers does not modify bone mass acquisition: a 1-year follow-up study
}

Laurent Maïmoun, Olivier Coste, Pascal Philibert, Karine Briot, Thibault Mura, Florence Galtier, Barbara Castes-De-Paulet, Denis Mariano-Goulart, Charles Sultan, Françoise Paris

\section{To cite this version:}

Laurent Maïmoun, Olivier Coste, Pascal Philibert, Karine Briot, Thibault Mura, et al.. Testosterone secretion in elite adolescent swimmers does not modify bone mass acquisition: a 1-year follow-up study. Fertility and Sterility, 2013, 99 (1), pp.270-278. 10.1016/j.fertnstert.2012.08.020 . hal-02548141

\section{HAL Id: hal-02548141 \\ https://hal.umontpellier.fr/hal-02548141}

Submitted on 20 Apr 2020

HAL is a multi-disciplinary open access archive for the deposit and dissemination of scientific research documents, whether they are published or not. The documents may come from teaching and research institutions in France or abroad, or from public or private research centers.
L'archive ouverte pluridisciplinaire HAL, est destinée au dépôt et à la diffusion de documents scientifiques de niveau recherche, publiés ou non, émanant des établissements d'enseignement et de recherche français ou étrangers, des laboratoires publics ou privés. 


\title{
Testosterone secretion in elite adolescent swimmers does not modify bone mass acquisition: a 1-year follow-up study
}

\author{
Laurent Maïmoun, Ph.D., ${ }^{a}$ Olivier Coste, M.D., Ph.D., ${ }^{a, b}$ Pascal Philibert, PharmD, Ph.D., ${ }^{a}$ \\ Karine Briot, M.D., Ph.D., ${ }^{c}$ Thibault Mura, M.D., d,e Florence Galtier, M.D., Ph.D., e,f \\ Barbara Castes-de-Paulet, PharmD, ${ }^{a}$ Denis Mariano-Goulart, M.D., Ph.D., ${ }^{9}$ Charles Sultan, M.D., Ph.D., ${ }^{a, h}$ \\ and Françoise Paris, M.D., Ph.D. ${ }^{a, h}$
}

a Département d'Hormonologie, Hôpital Lapeyronie, CHRU Montpellier et UMI; ${ }^{b}$ Direction Régionale de la Jeunesse, des Sports et de la Cohésion Sociale; ' Service de Rhumatologie, Hôpital Cochin, APHP Paris; ${ }^{d}$ Centre d'Investigation Clinique et Département d'information Médicale, CHRU Montpellier; ${ }^{\text {e }} \mathrm{CIC}$ 1001, INSERM; ${ }^{\dagger}$ Centre d'Investigation Clinique et Département des Maladies Endocriniennes, CHRU Montpellier; ${ }^{9}$ Service de Médecine Nucléaire, Hôpital Lapeyronie, CHRU Montpellier; and $\mathrm{h}$ Unité d'Endocrinologie et Gynécologie Pédiatrique, Hôpital A. de Villeneuve, CHRU Montpellier et UMI, Montpellier, France

Objective: To investigate whether high plasma testosterone (T) levels affect areal bone mineral density (aBMD), bone geometry, and bone remodeling in young elite female swimmers (SW).

Design: Cross-sectional and 1-year follow-up study.

Setting: Pediatric endocrinology and gynecology units.

Participant(s): Twenty-five SW and 21 control subjects (CON) with breast stages IV or V (mean age $15.3 \pm 1.3$ y).

Intervention(s): None.

Main Outcome Measure(s): Clinical and biologic parameters, aBMD, and bone geometry.

Result(s): Two groups of SW were constituted on the basis of total T level. High T level SW (HSW; $\mathrm{n}=15)$ presented higher T than SW with normal T (NSW; $\mathrm{n}=10)$ and CON $(0.63 \pm 0.17 ; 0.36 \pm 0.07$, and $0.38 \pm 0.14 \mathrm{ng} / \mathrm{mL}$, respectively). The SHBG level (62.1 \pm 18.7 vs. $43.3 \pm 19.8 \mathrm{nmol} / \mathrm{L})$ and the $\mathrm{LH} / \mathrm{FSH}$ ratio (1.7 \pm 1.1 vs. $0.9 \pm 0.5)$ were higher, and menstrual disorders $(60 \%$ vs. $23.8 \%)$ were more frequent in HSW than CON, and no difference was observed between the three groups for other sex hormones and insulin-like growth factor (IGF) 1 or IGF-binding protein 3. SW presented lower fat mass in the whole body and higher lean mass in the upper limbs only. aBMD was only modestly increased in the upper limbs in the SW groups, but no other bone-specific differences (aBMD, bone geometry, bone turnover markers) were demonstrated between SW and CON at baseline or for aBMD after 1 year in a subgroup of participants. Conclusion(s): High plasma T levels have no detectable effect on bone mass and bone geometry in SW during the period of peak bone mass acquisition.

Key Words: High plasma testosterone levels, intensive training, swimmers, adolescent girls, PCOS-like, bone mass acquisition

L.M. has nothing to disclose. O.C. has nothing to disclose. P.P. has nothing to disclose. K.B. has nothing to disclose. T.M. has nothing to disclose. F.G. has nothing to disclose. B.C.-d.-P. has nothing to disclose. D.M.-G. has nothing to disclose. C.S. has nothing to disclose. F.P. has nothing to disclose. Supported by grants from the Comité de Protection et de Lutte contre le Dopage (CPLD), the Institut Danone, and the Direction Régionale Jeunesse Sports et Cohésion Sociale (DRDJSCS) Montpellier.

Reprint requests: Charles Sultan, M.D., Ph.D., Unité d'Endocrinologie et Gynécologie Pédiatrique, Hôpital Arnaud de Villeneuve, 191 avenue Doyen Gaston Giraud, 34000 Montpellier, France (E-mail: c-sultan@chu-montpellier.fr).

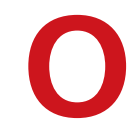
ur group recently reported a high prevalence of high total testosterone (T) levels associated with oligomenorrhea in young elite female swimmers (SW) compared with untrained adolescents (1). Other endocrine findings (high LH/FSH ratio and normal DHEAS and 17-0HP levels) suggested functional ovarian hyperandrogenism. Moreover, ultrasound 
confirmed a polycystic ovary (PCOS)-like syndrome in most of these swimmers (1).

In non-intensively trained adolescents, PCOS, which is characterized by hyperandrogenemia, chronic anovulation, and central adiposity, provides a unique natural model for the study of androgenic hormone influences on bone mass $(2,3)$. Androgens have direct stimulatory effects on bone cells through androgen receptors (4) or estrogen receptors (particularly ER-a) in osteoblasts (5) after their aromatization into estrogens (6). Various studies have attempted to demonstrate that the androgen overproduction and high serum estrogen levels usually observed in PCOS may counterbalance the deleterious effects of oligomenorrhea or amenorrhea on bone $(7,8)$. In these cases compared with other menstrual dysfunctions, bone status seems to be preserved (7-10). The question of additional bone mass gain due to the overproduction of plasma total $\mathrm{T}$ nevertheless remains controversial and may depend on menstrual disorder status (8). Moreover, other endocrine parameters modified in PCOS may also modulate bone cell activity. Insulin resistance and hyperinsulinemia may protect against bone mineral loss in women with PCOS $(3,9)$. Insulin directly stimulates osteoblastic activity and indirectly reduces the production of various proteins (SHBG and IGFBP) that increase free $\mathrm{T}$ and insulin-like growth factor (IGF) 1, which stimulate bone mass acquisition $(3,11)$.

Given the negative effect of menstrual disorders in highly trained girls (12), the hypothesis that high T levels can preserve bone health in elite adolescent swimmers during peak bone mass acquisition should be investigated (13). Although high $\mathrm{T}$ levels have been reported in other groups of endurance and power athletes $(14,15)$, the impact on bone mass has never been investigated in female athletes. The limited mechanical impact of swimming on bone provides a unique opportunity to evaluate the effects of the endocrine parameters, such as $\mathrm{T}$ overproduction, that are potentially modified by intensive training.

The aim of the present study was to determine whether high $\mathrm{T}$ levels affect areal bone mineral density (aBMD), bone geometry, bone remodeling or body composition in elite adolescent swimmers. Sex hormones, IGF-1 and IGF-binding protein (BP) 3 were investigated as potentially involved in bone metabolism. Last, in a subgroup of adolescents, the effect of high $\mathrm{T}$ levels on bone mass gain was evaluated 1 year later.

\section{SUBJECTS AND METHODS}

\section{Subjects}

The study protocol was reviewed and approved by the Regional Research Ethics Committee (CPP Sud-Mediterranee IV, Montpellier, France), and each child and her parents gave written informed consent before entering the study. A total of 46 postmenarcheal girls with ages ranging from 12 to 18.1 years (mean $15.5 \pm 1.3$ ), some of whom had been presented in an earlier study (1), were recruited for this casecontrol study. All of the participants presented breast stage IV or V (and pubic hair V). Moreover, as oligomenorrhea is common in adolescence, usually occurring immediately after the onset of menarche, only subjects with gynecologic age $>18$ months were included (16). Swimmers (SW) and control subjects (CON) were excluded if they used hormonal contraceptives or medications able to modify bone metabolism. Moreover, none presented obvious signs of acute or chronic illness known to affect bone health, and none reported a long period of immobilization or fracture within the past 12 months. All of the participants were white. SW were eligible if the training volume was $\geq 10$ hours per week and if the intensive training history was $>5$ years. All the SW were recruited in high level clubs in and around Montpellier. Nonobese age- and ethnicity-matched CON were eligible if they performed only leisure physical activities for $<4$ hours per week and if they had no history of intensive training. They were recruited from secondary schools in the Montpellier district or among recreational swimmers.

Twenty-five SW with a mean training volume of $15.2 \pm$ 4.4 hours per week were assigned to two subgroups according to their T levels: 15 composed the high T level SW group (HSW; $\mathrm{T} \geq 0.5 \mathrm{ng} / \mathrm{mL}$ ) and 10 composed the normal $\mathrm{T}$ level SW group (NSW; T $<0.5 \mathrm{ng} / \mathrm{mL}$ ). In adolescents, $0.5 \mathrm{ng} / \mathrm{mL}$ is the normal upper limit for $\mathrm{T}(17,18)$. Twenty-one CON with a mean training volume of $1.8 \pm 1.2$ hours per week were included in this study.

Among the population initially evaluated, ten HSW, seven NSW, and eight CON were reassessed 1 year later. SW withdrew from the longitudinal study for the following reasons: reduced or ended training $(\mathrm{n}=3)$, moved to another city for training $(n=2)$, and began hormonal contraceptive use $(\mathrm{n}=2)$. For CON, the major reasons for withdrawing were the following: began hormonal contraceptive use $(\mathrm{n}=$ $8)$, wanted to end study participation $(n=3)$, and moved away $(\mathrm{n}=2)$.

\section{Methods}

This study followed the same design described in detail in earlier publications (1, 19-21). Standing height was measured with a stadiometer to the nearest $0.1 \mathrm{~cm}$. Weight was determined using a weight scale with a precision of 0.1 $\mathrm{kg}$. Body mass index (BMI) was calculated as weight divided by the square of height $\left(\mathrm{kg} / \mathrm{m}^{2}\right)$. Pubertal development was assessed by breast stages according to the Tanner classification (22) by an experienced pediatric endocrinologist. Skeletal age was determined with the Greulich and Pyle method (23). Height standard deviation score (height SDS) and weight standard deviation score (weight SDS) were calculated according to the French standard curves.

Medical and menstrual histories. Each subject responded to a medical questionnaire designed to assess general medical and menstrual history with questions regarding the age of menarche and the pattern of menses, including duration of the menstrual cycle, duration of menstrual bleeding, absence of menstruation, and painful menstruation. Secondary amenorrhea (absence of menstruation for $>3$ months in the postmenarche period and in the absence of pregnancy [16]) and oligomenorrhea (two or more menstrual cycles of $<22$ days or $>41$ days during the past year [24]) were defined as 
menstrual disorders. The incidence and relative intensity of clinical signs of hyperandrogenism (acne, hirsutism) were recorded. Hirsutism was graded according to the criterion standard Ferriman-Gallwey score, by which the density of terminal hairs is scored at nine different body sites (25). In each of these areas, a score of 0-4 was assigned. A total score of $>8$ defined hirsutism. Acne was graded according to the Pillsbury method, which counts acne lesions to rank severity into grade I (absent or minor, 1-9 comedones), grade II (mild, 10-19 comedones), grade III (moderate, $\geq 20$ comedones, \pm inflammation), and grade IV (severe) (26).

Physical activity determination. Detailed information about the training history was collected, including data on the starting age of intensive training, years of active sport-specific training, and number of training sessions per week, training hours per week, and training months per year. Other physical activities were documented with a training recall diary covering the previous 3 years.

Endocrine assays. Blood samples $(25 \mathrm{~mL})$ were collected in the morning (9:00-11:00) during the early follicular phase in sterile chilled tubes by standard venipuncture technique. The samples were allowed to clot at room temperature and then centrifuged at $2,500 \mathrm{rpm}$ for 10 minutes at $4^{\circ} \mathrm{C}$. Plasma and serum samples were stored at $-80^{\circ} \mathrm{C}$ until analysis. All samples were run in duplicate and, to reduce interassay variation, all of the plasma samples were analyzed in a single session. The following hormones were analyzed: $\mathrm{E}_{2}$ (Biomerieux), T (Immunotech), free T (Coat-A-Count Free Testosterone; Siemens Healthcare Diagnostics), SHBG (Immulite 2000 SHBG; Siemens Healthcare Diagnostics), 17-0H progesterone (17-OHP; OHP-CT kit; CIS Bio International), DHEAS (DHEA-SO ${ }_{4}$; Siemens), delta-4-androstenedione (A; R-GM100; CIS Bio International), LH (Vidas LH; Biomerieux), FSH (Vidas FSH; Biomerieux Marcy-l'Etoile), IGF-1 (Diagnostic Systems Laboratories), and IGFBP-3 (IRMA; Immunotech). The respective intra-assay and interassay coefficients of variation (CVs) were as follows: $\mathrm{E}_{2}$ (4.2\% and 5.1\%), T (7\% and $<4 \%$ ), free T (6.2\% and 9.7\%), SHBG (6.1\% and 5.5\%), 17-0HP (2.74\% and 2.94\%), DHEAS (8\% and 9.8\%), A (5.6\% and $6 \%$ ), $\mathrm{LH}(4.8 \%$ and $6.6 \%)$, FSH (4.9\% and $3.5 \%)$, IGF-1 (2.4\% and 4.7\%), and IGFBP-3 (4.8\% and 5.2\%). The detection limits for $\mathrm{T}$, free $\mathrm{T}$, and SHBG were $0.1 \mathrm{ng} / \mathrm{mL}$, $0.25 \mathrm{pg} / \mathrm{mL}, 1.2 \mathrm{nmol} / \mathrm{L}$, respectively.

Regarding bone metabolism, plasma samples were assayed by Cobas 6000 (Roche Diagnostic, Mannheim, Germany) for osteocalcin (OC), procollagen type I N-terminal propeptide (PINP), and type I-C telopeptide breakdown products (CTX). The inter- and intra-assay CVs for the three parameters were $<7 \%$.

Bone mineral density, body fat, and lean tissue mass. Dualenergy x-ray absorptiometry (DXA; Hologic QDR-4500A) was used to measure the areal bone mineral density (aBMD; $\mathrm{g} / \mathrm{cm}^{2}$ ) of the whole body and at other specific bone sites: the anteroposterior lumbar spine (L1-L4), the dominant arm radius, the proximal part of the left femur, and specific sites of the femoral neck and the trochanteric and intertrochanteric areas. The soft tissue body composition [fat mass (FM, kg), percentage of body fat mass (\%FM), and lean mass (LM, $\mathrm{kg})$ ] was derived from the whole body scan. All scanning and analyses were performed by the same operator to ensure consistency and followed standard quality control procedures. Quality control for DXA was checked daily by scanning a lumbar spine phantom consisting of calcium hydroxyapatite embedded in a cube of thermoplastic resin (Hologic x-caliber anthropometric spine phantom). For BMD, the laboratory precision error was defined by the CV of repeated measurements; this was found to be $1 \%$ at the lumbar spine, $<1 \%$ at the femoral neck, $<1 \%$ at the forearm, $<0.5 \%$ for the whole body, and $<1 \%$ for LM and FM. Identical and accurate positioning of the region of interest was ensured by superimposing the image from the first session on the image of the explored bone area; the initial image thus served as the visual reference.

Bone geometry of the proximal femur. Using DXA data, we analyzed hip geometry parameters with hip structural analysis (HSA) software (27). The HSA program uses mineral mass and dimensional data from conventional DXA images of the hip to measure the structural dimensions of bone crosssections corresponding to three thin regions traversing the proximal femur: the narrow-neck (NN) region across the narrowest point of the femoral neck, the intertrochanteric (IT) region across the bisector of the neck and shaft axes, and the shaft region located at a distance 1.5 times the width of the femoral neck distal from the intersection of the neck and shaft axes. For each region, the HSA program computed the following variables: 1) the bone cross-sectional area (in $\mathrm{cm}^{2}$ ), an index of resistance to axial forces; 2 ) the section modulus ( $Z$; in $\mathrm{cm}^{3}$ ), an index of strength in bending computed from the cross-sectional moment of inertia that weights the area in the cross-section by the square of its distance from the centroid; 3) the estimated average cortical thickness; and 4) the buckling ratio, an index of susceptibility to local cortical buckling under compressive loads. HSA precision has not yet been assessed in children and adolescents; however, experience in mainly elderly populations has shown HSA precision on the order of 1\%-5\% for the HSA parameters at the three HSA regions (28). All values were also adjusted to body weight and body height. A single doctor conducted all software analyses.

\section{Statistical Analysis}

The characteristics of the young athletes in the present study are described with proportions for categoric variables and with means and SD values for continuous variables (age, weight, aBMD, etc.). The distributions were tested with the Shapiro-Wilk statistic. The comparisons of means between the swimmers and control subjects (or subgroups according to androgenic status) were performed with the use of analysis of variance when data distribution was normal and the Kruskall-Wallis test if continuous variables were skewed. For each aBMD site, adjusted means for age, FM, and LM were computed and compared between groups with the use of multivariate linear regression analysis. Bone geometry and strength as calculated from values at the femur adjusted for height and weight were also compared. The familywise error rate was controlled with the use of Ryan (REGWQ, for 
crude analysis) and Tukey (for adjusted analysis) multiple comparison procedures. The relationships between continuous parameters were assessed with the Spearman correlation coefficient and adjusted with the partial Spearman correlation coefficient.

Statistical analyses were performed at the conventional two-tailed $\alpha$ level of .05 using SAS version 9.1.

\section{RESULTS}

\section{Anthropometric Data and Training Status}

The baseline anthropometric and body composition parameters, as well as the training status of SW and CON groups, are reported in Table 1. The groups were similar regarding age, bone age, weight, height, and BMI. The weight and height SDS were normal, according to the French reference curves. Fat mass (\%) was significantly reduced in both SW groups compared with CON at whole body, lower limbs, upper limbs, and trunk, but lean tissue mass was higher in the SW groups only at upper limbs. The hours of training per week tended to be higher in NSW (17.0 $\pm 5.2 \mathrm{~h} / \mathrm{wk})$ compared with HSW (13.9 $\pm 3.5 \mathrm{~h} / \mathrm{wk}$ ), but the difference did not reach significance.

\section{Clinical Data}

The clinical data for the three groups are presented in Table 2. The age of menarche was not significantly different between groups $(12.5 \pm 1.3 \mathrm{y}, 12.9 \pm 1.3 \mathrm{y}$, and $12.3 \pm 1.4 \mathrm{y}$ for HSW, NSW and CON, respectively). The prevalence of menstrual disorders was higher in SW groups compared with CON (60\% vs. $23.8 \% ; P=.031$ ). Intriguingly, no difference in this prevalence was observed between the two SW groups. In the HSW group only, three cases of secondary amenorrhea were observed. Signs of hyperandrogenism were observed in nine HSW (60\%) and five NSW (50\%). Although higher than in CON (33.3\%), these percentages were not significantly different from the $\mathrm{CON}$ percentage.

\section{Endocrine Assays}

The values of basal serum hormones are presented in Table 2. Serum T levels were significantly higher in HSW $(0.63 \pm 0.10$ $\mathrm{ng} / \mathrm{mL})$ compared with NSW $(0.36 \pm 0.07 \mathrm{ng} / \mathrm{mL})$ and CON $(0.38 \pm 0.14 \mathrm{ng} / \mathrm{mL})$. In the CON group, only five subjects were classified as having high total $\mathrm{T}$ levels $(\mathrm{T}>0.5 \mathrm{ng} /$ $\mathrm{mL}$ ). Free $\mathrm{T}$ was not significantly different among the three groups, although HSW tended to have higher values than CON (1.65 \pm 0.47 vs. $1.37 \pm 0.55 \mathrm{pg} / \mathrm{mL}$, respectively; $P=.1)$. SHBG levels were significantly higher in HSW compared with CON $(P=.021)$, and no difference was observed between HSW and NSW. The mean LH/FSH ratio in HSW was higher than in CON $(1.7 \pm 1.1$ vs. $0.9 \pm 0.5 ; P<.033)$ but did not differ from NSW (1.3 \pm 1.2$)$. No other differences were observed for the other sex hormones and IGF-1 or IGFBP-3. After 1 year, $<30 \%$ of SW presented a variation in $\mathrm{T}$ levels sufficient to cross the cutoff point of $0.5 \mathrm{ng} / \mathrm{mL}$ and thus be put into the other T group (HSW to NSW [n = 3] or NSW to HSW [n = 2]).

\section{TABLE 1}

Age, anthropometry, body composition, and training status of swimmers and control girls at baseline.

\begin{tabular}{|c|c|c|c|c|}
\hline Parameter & Swimmers, high T & Swimmers, normal T & Control girls & Global $P$ value \\
\hline No. of subjects & 15 & 10 & 21 & \\
\hline Age $(y)$ & $15.0 \pm 1.3$ & $14.9 \pm 0.9$ & $15.6 \pm 1.6$ & .138 \\
\hline Bone age (y) & $15.9 \pm 0.8$ & $15.4 \pm 0.7$ & $15.7 \pm 1.2$ & .331 \\
\hline \multicolumn{5}{|l|}{ Anthropometric data } \\
\hline Weight (kg) & $55.6 \pm 5.8$ & $52.8 \pm 4.6$ & $56.4 \pm 8.2$ & .399 \\
\hline Weight SDS & $0.8 \pm 1.1$ & $0.4 \pm 0.7$ & $0.9 \pm 1.3$ & .573 \\
\hline Height $(\mathrm{cm})$ & $164.7 \pm 5.2$ & $162.7 \pm 5.1$ & $162.4 \pm 5.4$ & .440 \\
\hline BMI $\left(\mathrm{kg} / \mathrm{m}^{2}\right)$ & $20.6 \pm 2.0$ & $19.9 \pm 1.2$ & $21.4 \pm 2.9$ & .498 \\
\hline \multicolumn{5}{|l|}{ Fat mass (kg) } \\
\hline Whole body & $11.5 \pm 3.4$ & $10.3 \pm 1.9$ & $14.3 \pm 6.2$ & .065 \\
\hline Lower limb & $2.7 \pm 0.8$ & $2.5 \pm 0.5$ & $3.5 \pm 1.2$ & .031 \\
\hline Upper limb & $0.7 \pm 0.2^{a, b}$ & $0.6 \pm 0.1^{a}$ & $0.9 \pm 0.4^{b}$ & .006 \\
\hline Trunk & $3.9 \pm 1.4^{a, b}$ & $3.3 \pm 0.7^{a}$ & $5.2 \pm 2.4^{b}$ & .043 \\
\hline \multicolumn{5}{|l|}{ Fat mass (\%) } \\
\hline Whole body & $20.5 \pm 4.8^{a}$ & $19.3 \pm 2.7^{a}$ & $25.6 \pm 5.8^{b}$ & .002 \\
\hline Upper limb & $19.6 \pm 5.9^{a}$ & $17.9 \pm 2.7^{a}$ & $27.8 \pm 7.6^{b}$ & $<.001$ \\
\hline Trunk & $15.6 \pm 4.6^{a}$ & $14.0 \pm 2.4^{a}$ & $20.2 \pm 6.1^{b}$ & .004 \\
\hline \multicolumn{5}{|l|}{ Lean tissue mass $(\mathrm{kg})$} \\
\hline Whole body fat-free soft tissue & $42.2 \pm 4.1$ & $40.6 \pm 3.1$ & $39.7 \pm 3.9$ & .166 \\
\hline Lower limb & $6.9 \pm 0.8$ & $6.4 \pm 0.7$ & $6.4 \pm 1.1$ & .112 \\
\hline Upper limb & $2.6 \pm 0.4^{a}$ & $2.5 \pm 0.2^{a}$ & $2.0 \pm 0.3^{b}$ & $<.001$ \\
\hline Trunk & $20.3 \pm 2.3$ & $20.0 \pm 1.3$ & $19.4 \pm 2.2$ & .432 \\
\hline \multicolumn{5}{|l|}{ Training status } \\
\hline Hours/week & $13.9 \pm 3.5^{a}$ & $17.0 \pm 5.2^{\mathrm{a}}$ & $1.8 \pm 1.2^{b}$ & $<.001$ \\
\hline Age at start of training (yr) & $6.5 \pm 2.3$ & $7.1 \pm 2.3$ & $8.3 \pm 3.4$ & .463 \\
\hline \multicolumn{5}{|c|}{$\begin{array}{l}\text { Note: Values are presented as mean } \pm \text { SD. BMI = body mass index; } S D S=\text { standard deviation score. } \\
\text { a,b Groups with the same letter are not significantly different. }\end{array}$} \\
\hline \multicolumn{5}{|c|}{ Maïmoun. Testosterone and bone mass in swimmers. Fertil Steril 2013.} \\
\hline
\end{tabular}




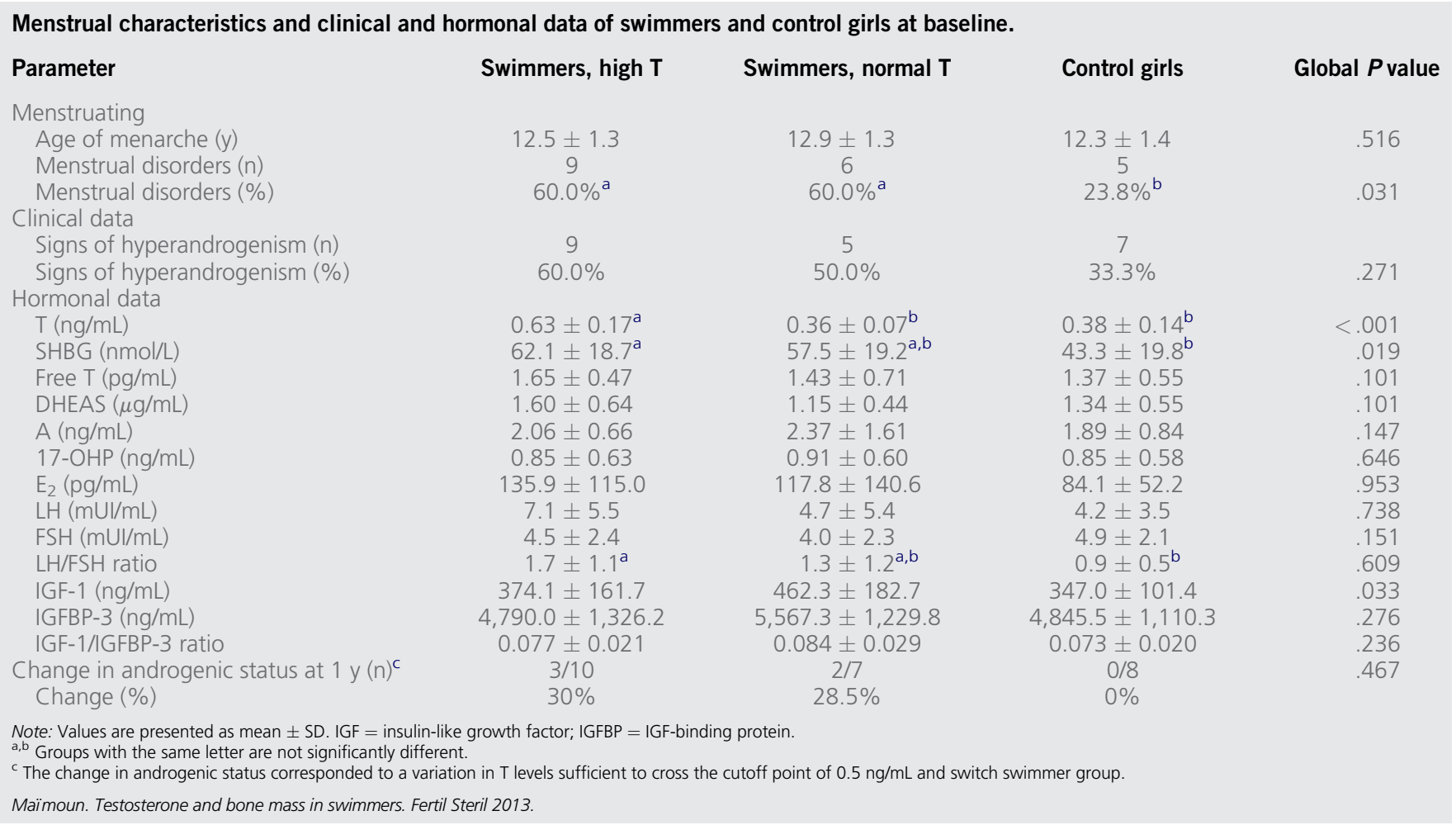

\section{Bone Status}

Unadjusted aBMD and aBMD adjusted for age, FM, and LM did not differ significantly among the three groups at whole body, femoral region, lumbar spine, or radius (Table 3). Only aBMD at the upper limb was increased in the two SW groups compared with CON. Figure 1 shows the mean change in adjusted aBMD after 1 year at various bone sites in a subgroup of HSW $(n=10)$, NSW $(n=7)$, and CON $(n=$ 8). No difference in adjusted aBMD variation at 1 year was found among the groups. Only aBMD at the pelvis tended to increase more rapidly in NSW than HSW $(P=.06)$ and CON $(P=.07)$.

Bone geometry or bone strength parameters were similar among groups at the femoral neck, intertrochanteric region, and femoral shaft. Table 3 presents the results evaluated only at the femoral neck.

Regarding markers of bone turnover (Table 3), no difference was observed among the groups for the markers of bone formation (OC and PINP) and resorption (CTX).

Correlation analysis of hormone parameters (androgen and IGF-1) and aBMD at various bone sites across the three groups $(n=46)$ was performed. Significant but low negative correlations were observed between total $\mathrm{T}$ and $\mathrm{aBMD}$ at the femoral neck $(r=-0.278 ; P=.05)$ and intertrochanter $(r=$ $-0.322 ; P=.03$ ). These correlations persisted when aBMD was adjusted for age, FM, and LM (femoral neck: $r=$ -0313 [ $P=.04]$; intertrochanter: $r=-0.283[P=.05]$ ]). Other relationships were significant only when aBMD was adjusted (pelvis: $r=-0.313[P=.04]$; trochanter: $r=-0.310[P=.04]$; total proximal femur: $r=-0.286[P=.05]]$. SHBG was negatively correlated with unadjusted aBMD at the total proximal femur $(r=-0.273 ; P=.05)$ and radius $(r=-0.320 ; P=.03)$ but not when aBMD was adjusted.

No other correlation was found between sex hormones or IGF-1 and aBMD measured at other bone sites or bone geometry parameters evaluated at the femoral neck.

\section{DISCUSSION}

Our results clearly demonstrate for the first time that swimming did not modify bone mass acquisition, bone geometry, or bone remodeling in a homogeneous group of highly trained adolescents during the peripubertal period, whatever the T level.

The lack of an osteogenic effect of intensive swimming training is in line with the findings of earlier studies that evaluated prepubertal girls $(29,30)$, postpubertal girls (31), and adult men and women (32-34). Regarding girls, however, none of those works attempted to evaluate the relationship between androgenic status and bone mass. It seems that in the absence of high mechanical loading, the transmission of forceful muscle contractions alone, which characterizes swimming, is not sufficient to induce bone mass gain $(29,32,33)$. Conversely, we recently reported in young artistic gymnasts, who undergo high mechanical loading, a beneficial effect not only on aBMD, but also on bone geometry (21). Although the gymnasts presented a high incidence of menstrual abnormalities, the negative effect of low estrogen levels may thus have been counterbalanced by the effects of high mechanical strain $(21,35)$.

The clinical, and more particularly the hormonal, profile of the HSW group was quite surprising because several signs of hyperandrogenism and menstrual disorders are associated 
Adjusted areal bone mineral density at various bone sites, bone geometry at the femoral neck and markers of bone turnover of swimmers and control girls at baseline.

\begin{tabular}{|c|c|c|c|c|}
\hline Parameter & Swimmers, high T & Swimmers, normal T & Control girls & Global $P$ value \\
\hline \multicolumn{5}{|l|}{ Bone mineral density $\left(\mathrm{g} / \mathrm{cm}^{2}\right)^{c}$} \\
\hline Whole body & $1.030 \pm 0.018$ & $1.057 \pm 0.022$ & $1.031 \pm 0.016$ & .583 \\
\hline Lower limb & $1.038 \pm 0.017$ & $1.070 \pm 0.021$ & $1.060 \pm 0.0151$ & .444 \\
\hline Upper limb & $0.739 \pm 0.010^{a}$ & $0.748 \pm 0.013^{a}$ & $0.707 \pm 0.009^{b}$ & .040 \\
\hline Pelvis & $1.115 \pm 0.027$ & $1.151 \pm 0.033$ & $1.195 \pm 0.024$ & .133 \\
\hline Total proximal femur & $0.897 \pm 0.026$ & $0.934 \pm 0.031$ & $0.966 \pm 0.022$ & .177 \\
\hline Neck & $0.805 \pm 0.027$ & $0.858 \pm 0.033$ & $0.859 \pm 0.023$ & .285 \\
\hline Trochanter & $0.690 \pm 0.022$ & $0.751 \pm 0.027$ & $0.749 \pm 0.019$ & .106 \\
\hline Intertrochanter & $1.031 \pm 0.031$ & $1.091 \pm 0.038$ & $1.091 \pm 0.028$ & .326 \\
\hline Lumbar spine (L1-L4) & $0.907 \pm 0.025$ & $0.929 \pm 0.030$ & $0.948 \pm 0.022$ & .492 \\
\hline Radius & $0.516 \pm 0.010$ & $0.532 \pm 0.011$ & $0.527 \pm 0.008$ & .561 \\
\hline \multicolumn{5}{|l|}{ Bone geometry at femoral neck ${ }^{d}$} \\
\hline CSA $\left(\mathrm{cm}^{2}\right)$ & $2.789 \pm 0.094$ & $3.028 \pm 0.102$ & $2.898 \pm 0.072$ & .252 \\
\hline $\operatorname{CSMI}\left(\mathrm{cm}^{4}\right)$ & $2.040 \pm 0.127$ & $2.272 \pm 0.139$ & $2.038 \pm 0.098$ & .352 \\
\hline Section modulus $\left(Z ; \mathrm{cm}^{3}\right)$ & $1.248 \pm 0.065$ & $1.449 \pm 0.071$ & $1.306 \pm 0.050$ & .120 \\
\hline Endocortical diameter (cm) & $2.665 \pm 0.086$ & $2.585 \pm 0.093$ & $2.570 \pm 0.066$ & .680 \\
\hline Width $(\mathrm{cm})$ & $3.042 \pm 0.075$ & $3.002 \pm 0.081$ & $2.973 \pm 0.058$ & .776 \\
\hline \multicolumn{5}{|l|}{ Markers of bone turnover } \\
\hline $\mathrm{OC}(\mathrm{ng} / \mathrm{mL})$ & $49.2 \pm 22.5$ & $60.2 \pm 13.3$ & $54.7 \pm 26.8$ & .180 \\
\hline PINP (ng/mL) & $161.6 \pm 92.4$ & $228.5 \pm 59.0$ & $193.6 \pm 142.0$ & .113 \\
\hline CTX (ng/mL) & $0.626 \pm 0.224$ & $0.722 \pm 0.174$ & $0.741 \pm 0.334$ & .446 \\
\hline \multicolumn{5}{|c|}{$\begin{array}{l}\text { Note: Values are presented as mean } \pm \text { SD. CSA }=\text { cross-sectional area; } C S M I=\text { cross-sectional moment of inertia; } C T X=\text { type I-C telopeptide breakdown products; OC }=\text { osteocalcin; PINP = } \\
\text { procollagen type I N-terminal propeptide. } \\
\text { a,b Groups with the same letter are not significantly different. } \\
\text { c aBMD was adjusted by age, body fat mass, and body fat-free soft tissue. } \\
\text { d Bone geometry parameters at femoral neck were adjusted for body height and body weight. }\end{array}$} \\
\hline \multicolumn{5}{|c|}{ Maïmoun. Testosterone and bone mass in swimmers. Fertil Steril 2013.} \\
\hline
\end{tabular}

with normal free T and high SHBG concentrations. A number of studies have demonstrated that intensive swimming training in women $(36,37)$ may induce a decrease in $\mathrm{T}$ along with an increase in SHBG. In an earlier study, our group suggested that $\mathrm{T}$ may have been higher at the beginning of swimming training in the HSW group than in the CON group (1). Given these clinical and biologic observations, the HSW group can not be defined as "hyperandrogenic." Interestingly, the hormonal profile of NSW was similar to that of CON and differed from that of HSW only for T levels.

The favorable role of estrogen and IGF-1 on bone mineralization during puberty in girls has been widely acknowledged $(38,39)$, whereas the role of $\mathrm{T}$ is still under debate $(38,40)$. A recent longitudinal study demonstrated that $\mathrm{T}$ levels were positively associated with cortical volumetric BMD only before menarche and with periosteal circumference throughout peripubertal growth (39). These results suggest that $\mathrm{T}$ promotes bone mass accrual in girls at an early age by enhancing periosteal bone formation (41), as previously demonstrated in animal models (42), and by increasing bone mineralization. Moreover, it is probable that premenarcheal hormone levels have a crucial influence on the attainment of peak bone mass in later years (39). Although we lacked data regarding the hormone values before menarche, high T levels may have preceded the intensive training, predisposing these girls to this competitive sport (1). The follow-up at 1 year confirmed that the high T levels were persistent, because only $30 \%$ of the swimmers changed androgen-status groups.
In this environment of high $\mathrm{T}$ levels persisting for at least the 1-year period of our study, why did the HSW group not show a noticeable modification in bone status (aBMD, geometry, bone remodeling) compared with the NSW and CON groups? The most probable explanation is that the increase in SHBG limited the biologic activity of T. This hypothesis was confirmed by the direct measurement of normal values of free $\mathrm{T}$. Other factors may also explain the lack of greater BMD in swimmers. First, the high prevalence of menstrual disorders (60\%) in HSW may have altered the potentially favorable effects of intensive training and high T secretion, as previously demonstrated in PCOS patients $(8,43)$. In the present study, the limited number of swimmers per group did not allow us to subdivide our population according to menstrual status, although swimmers with PCOS and oligomenorrhea are potentially more at risk for the development of low bone mass than those with eumenorrhea. Second, it is plausible that individuals with lower or normal bone mass have an advantage in swimming, because the lower body density would enhance their buoyancy and maximize their lean body mass to power output $(29,32)$. Third, the cutoff of $0.5 \mathrm{ng} / \mathrm{mL}$ for $\mathrm{T}$ levels is debatable because although this threshold is unanimously accepted for the determination of hyperandrogenism (44), the $\mathrm{T}$ threshold value for improved bone mass gain in women and girls remains to be defined.

The hormonal profile of HSW is very specific and has not been reported in any patient populations. The study of young patients with PCOS may provide some insight regarding the 

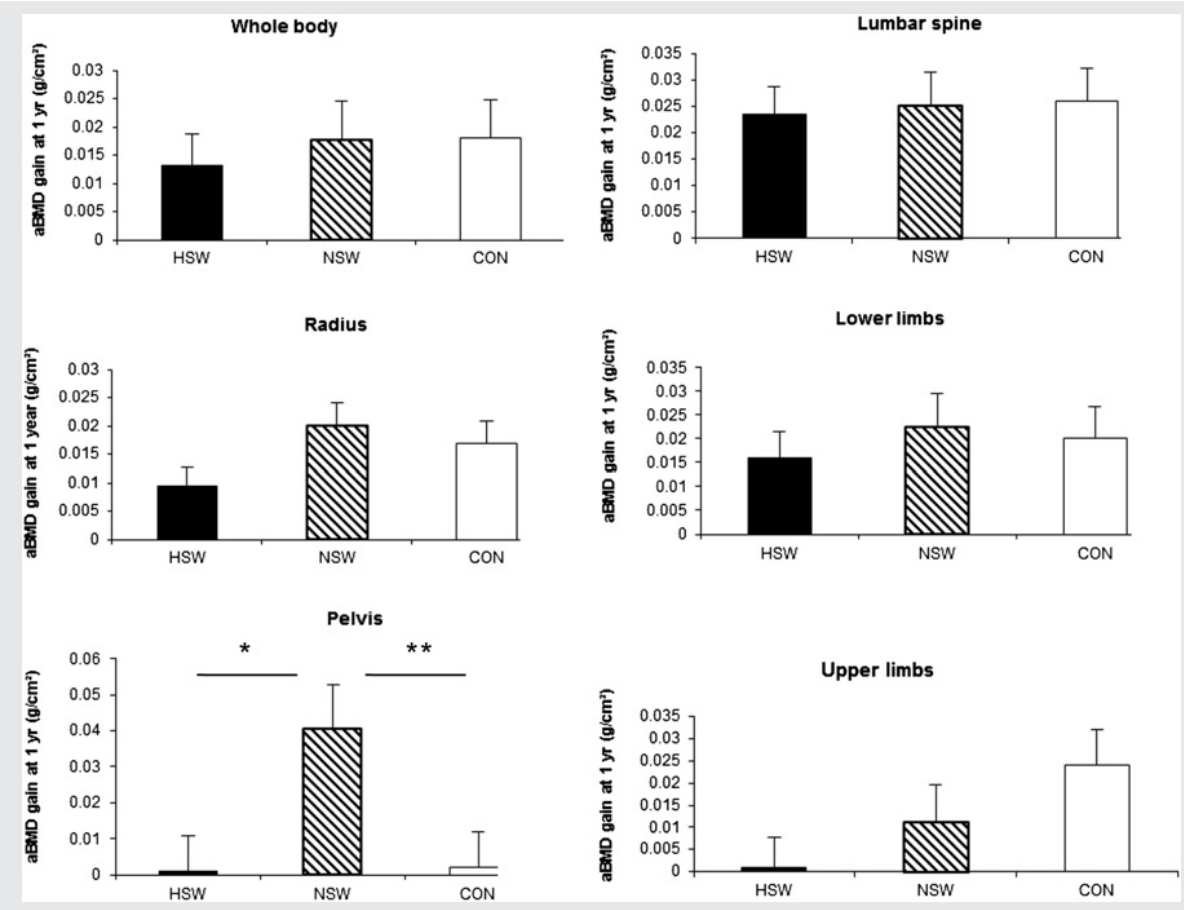

Adjusted areal bone mineral density gain at various bone sites at 1 year. Variation in areal bone mineral density (aBMD, g/ $\left.\mathrm{cm}^{2}\right)$ adjusted for age, fat mass, and lean mass at 1 year in a subgroup of adolescents: 10 swimmers with high testosterone levels (HSW; $T \geq 0.5 \mathrm{ng} / \mathrm{mL}$ ), $7 \mathrm{swimmers} \mathrm{with}$ normal testosterone levels (NSW; $T<0.5 \mathrm{ng} / \mathrm{mL}$ ), and 8 control subjects. Values are presented as mean $\pm \mathrm{SEM}$. * $P=.06$; **P=.07.

Maïmoun. Testosterone and bone mass in swimmers. Fertil Steril 2013.

probable action of high androgen levels on bone acquisition. It should be noted, however, that these patients generally present very high $\mathrm{T}$ levels associated with high free T and low SHBG, conversely to the HSW of our study $(2,3,45)$. Nevertheless, in agreement with our results, most studies have reported no aBMD difference between PCOS patients and control subjects $(2,3,7,8,10,43)$, although others reported lower (9) or modestly higher aBMD $(2,43)$. More recent works using peripheral quantitative computerized tomography have reported a modest but significantly greater cortical BMD at the distal tibia in adolescents and women with PCOS (10, 45). This suggests that hyperandrogenism may have a positive effect principally in the cortical bone compartment (periosteal envelope) and thus on bone strength (45). The DXA technique, which has been used in previous studies (2, $3,7,8,10,43)$ as well as in the present work, gives an integrated measure of both cortical and trabecular compartments at a given site. Consequently, we were unable to distinguish a potential impact of androgen excess on the cortical bone compartments $(11,45)$. The complementary HSA method was therefore used (46) to detect a potential effect on bone geometry. However, our results indicated no effect on the cortical envelope, because the endocortical diameter and mean cortical thickness were identical in the three groups. Nevertheless, this technique is indirect and has some technical limitations, and HSA data are particularly lacking during growth and adolescence (21). Other indirect findings point to the positive effect of $\mathrm{T}$ on bone in PCOS patients as well as, e.g., the deleterious effects of antiandrogen drugs on bone metabolism (47).

The hormonal data reported in our study should be taken into account with caution. In particular, hormone analysis was based on a single blood draw, although hormonal status may vary during the sports season, depending on the intensity level (36). However, as mentioned above, the 1-year follow-up in a subgroup of the swimmers suggested that the $\mathrm{T}$ levels were relatively stable over time. The hormonal assays were performed according to the manufacturers' recommendations (preanalytical and analytical treatment). Moreover, all analyses were performed at the same time to reduce interassay variability. Although the RIA technique is not the criterion standard for measuring plasma $T$ (48), the statement from the consensus meeting on hyperandrogenism, as well as the cutoff for pubertal girls, was based on RIA assays (18).

In conclusion, high $\mathrm{T}$ levels in swimmers did not have a detectable effect on bone mass acquisition, as demonstrated by normal aBMD, bone geometry, and bone remodeling. Among various factors, normal bioavailable $\mathrm{T}$ and a high prevalence of menstrual disorders may partly explain the normal bone status observed in the swimmers.

Acknowledgments: The authors express their thanks to the swimmers, the control subjects, and their parents for their participation. The authors thank also Marie-Agnès Martin for excellent technical assistance and Roche Diagnostics for 
providing the bone biochemical kits. The authors are indebted to the Departments of Radiopédiatrie for their excellent technical support.

\section{REFERENCES}

1. Coste O, Paris F, Galtier F, Letois F, Maimoun L, Sultan C. Polycystic ovarylike syndrome in adolescent competitive swimmers. Fertil Steril 2011;96: 1037-42.

2. Good C, Tulchinsky M, Mauger D, Demers LM, Legro RS. Bone mineral density and body composition in lean women with polycystic ovary syndrome. Fertil Steril 1999;72:21-5

3. Noyan $\vee$, Yucel A, Sagsoz N. The association of bone mineral density with insulin resistance in patients with polycystic ovary syndrome. Eur J Obstet Gynecol Reprod Biol 2004;115:200-5.

4. Colvard DS, Eriksen EF, Keeting PE, Wilson EM, Lubahn DB, French FS, et al. Identification of androgen receptors in normal human osteoblast-like cells. Proc Natl Acad Sci U S A 1989;86:854-7.

5. Lindberg MK, Vandenput L, Moverare Skrtic S, Vanderschueren D, Boonen S, Bouillon R, et al. Androgens and the skeleton. Minerva Endocrinol 2005;30:15-25.

6. Vandenput L, Swinnen JV, Boonen S, Van Herck E, Erben RG, Bouillon R, et al. Role of the androgen receptor in skeletal homeostasis: the androgen-resistant testicular feminized male mouse model. J Bone Miner Res 2004;19:1462-70

7. di Carlo C, Shoham Z, MacDougall J, Patel A, Hall ML, Jacobs HS. Polycystic ovaries as a relative protective factor for bone mineral loss in young women with amenorrhea. Fertil Steril 1992;57:314-9.

8. Adami S, Zamberlan N, Castello R, Tosi F, Gatti D, Moghetti P. Effect of hyperandrogenism and menstrual cycle abnormalities on bone mass and bone turnover in young women. Clin Endocrinol (Oxf) 1998;48:169-73.

9. Yuksel O, Dokmetas HS, Topcu S, Erselcan T, Sencan M. Relationship between bone mineral density and insulin resistance in polycystic ovary syndrome. J Bone Miner Metab 2001;19:257-62.

10. To WW, Wong MW. A comparison of bone mineral density in oligomenorrhoeic adolescents with polycystic ovaries and normal ovaries. Gynecol Endocrinol 2005;20:237-42.

11. Zborowski JV, Cauley JA, Talbott EO, Guzick DS, Winters SJ. Clinical review 116: bone mineral density, androgens, and the polycystic ovary: the complex and controversial issue of androgenic influence in female bone. J Clin Endocrinol Metab 2000;85:3496-506.

12. Warren MP, Chua AT. Exercise-induced amenorrhea and bone health in the adolescent athlete. Ann N Y Acad Sci 2008;1135:244-52.

13. Theintz G, Buchs B, Rizzoli R, Slosman D, Clavien H, Sizonenko PC, et al. Longitudinal monitoring of bone mass accumulation in healthy adolescents: evidence for a marked reduction after 16 years of age at the levels of lumbar spine and femoral neck in female subjects. J Clin Endocrinol Metab 1992;75: 1060-5.

14. Rickenlund A, Carlstrom K, Ekblom B, Brismar TB, von Schoultz B, Hirschberg AL. Hyperandrogenicity is an alternative mechanism underlying oligomenorrhea or amenorrhea in female athletes and may improve physical performance. Fertil Steril 2003;79:947-55.

15. Hagmar M, Berglund B, Brismar K, Hirschberg AL. Hyperandrogenism may explain reproductive dysfunction in olympic athletes. Med Sci Sports Exerc 2009;41:1241-8.

16. Golden NH, Carlson JL. The pathophysiology of amenorrhea in the adolescent. Ann N Y Acad Sci 2008;1135:163-78.

17. Sultan C, Paris F. Clinical expression of polycystic ovary syndrome in adolescent girls. Fertil Steril 2006;86(Suppl 1):S6.

18. Ankarberg C, Norjavaara E. Diurnal rhythm of testosterone secretion before and throughout puberty in healthy girls: correlation with 17beta-estradiol and dehydroepiandrosterone sulfate. J Clin Endocrinol Metab 1999;84: 975-84.

19. Maimoun L, Coste O, Galtier F, Mura T, Mariano-Goulart D, Paris F, et al. Bone mineral density acquisition in peripubertal female rhythmic gymnasts is directly associated with plasma IGF1/IGF-binding protein 3 ratio. Eur J Endocrinol 163:157-64
20. Maimoun L, Coste O, Jaussent A, Mariano-Goulart D, Sultan C, Paris F. Bone mass acquisition in female rhythmic gymnasts during puberty: no direct role for leptin. Clin Endocrinol (Oxf) 72:604-11.

21. Maimoun L, Coste O, Mariano-Goulart D, Galtier F, Mura T, Philibert P, et al. In peripubertal girls, artistic gymnastics improves areal bone mineral density and femoral bone geometry without affecting serum OPG/RANKL levels. Osteoporos Int 2011;22:3055-66.

22. Tanner J. Growth at adolescence. Oxford: Blackwell Scientific Publications, 1962.

23. Greulich WW, Pyle SI. Radiographic atlas of skeletal development of hand and wrist. 2nd ed. Stanford, California: Stanford University Press, 1959.

24. van Hooff $M H$, van der Meer M, Lambalk CB, Schoemaker J. Variation of luteinizing hormone and androgens in oligomenorrhoea and its implications for the study of polycystic ovary syndrome. Hum Reprod 1999;14: 1684-9.

25. Ferriman D, Gallwey JD. Clinical assessment of body hair growth in women. J Clin Endocrinol Metab 1961;21:1440-7.

26. Pillsbury DSW, Kligman AM, Shelley WB. A manual of cutaneous medicine. Philadelphia: Sauders, 1961

27. Beck TJ, Ruff CB, Warden KE, Scott WW Jr, Rao GU. Predicting femoral neck strength from bone mineral data. A structural approach. Invest Radiol 1990; 25:6-18.

28. Khoo BC, Beck TJ, Qiao QH, Parakh P, Semanick L, Prince RL, et al. In vivo short-term precision of hip structure analysis variables in comparison with bone mineral density using paired dual-energy x-ray absorptiometry scans from multi-center clinical trials. Bone 2005;37:112-21.

29. Cassell C, Benedict M, Specker B. Bone mineral density in elite 7- to 9-yr-old female gymnasts and swimmers. Med Sci Sports Exerc 1996;28:1243-6.

30. Courteix D, Lespessailles E, Peres SL, Obert P, Germain P, Benhamou CL. Effect of physical training on bone mineral density in prepubertal girls: a comparative study between impact-loading and nonimpact-loading sports. Osteoporos Int 1998;8:152-8.

31. Duncan CS, Blimkie CJ, Cowell CT, Burke ST, Briody JN, Howman-Giles R. Bone mineral density in adolescent female athletes: relationship to exercise type and muscle strength. Med Sci Sports Exerc 2002;34:286-94.

32. Taaffe DR, Snow-Harter C, Connolly DA, Robinson TL, Brown MD, Marcus R. Differential effects of swimming versus weight-bearing activity on bone mineral status of eumenorrheic athletes. J Bone Miner Res 1995; 10:586-93.

33. Maimoun L, Mariano-Goulart D, Couret I, Manetta J, Peruchon E, Micallef JP, et al. Effects of physical activities that induce moderate external loading on bone metabolism in male athletes. J Sports Sci 2004;22:875-83.

34. Hind K, Gannon L, Whatley E, Cooke C, Truscott J. Bone cross-sectional geometry in male runners, gymnasts, swimmers and nonathletic controls: a hip-structural analysis study. Eur J Appl Physiol 2012;112:535-41.

35. Robinson TL, Snow-Harter C, Taaffe DR, Gillis D, Shaw J, Marcus R. Gymnasts exhibit higher bone mass than runners despite similar prevalence of amenorrhea and oligomenorrhea. J Bone Miner Res 1995;10:26-35.

36. Cumming DC, Wall SR, Quinney HA, Belcastro AN. Decrease in serum testosterone levels with maximal intensity swimming exercise in trained male and female swimmers. Endocr Res 1987;13:31-41.

37. Wilmore JH, Costill DL, Kenney W. Physiology of sport and exercise. Champaign, Illinois: Human Kinetics, 2008

38. Yilmaz D, Ersoy B, Bilgin E, Gumuser G, Onur E, Pinar ED. Bone mineral density in girls and boys at different pubertal stages: relation with gonadal steroids, bone formation markers, and growth parameters. J Bone Miner Metab 2005;23:476-82.

39. Xu L, Wang Q, Lyytikainen A, Mikkola T, Volgyi E, Cheng S, et al. Concerted actions of insulin-like growth factor 1 , testosterone, and estradiol on peripubertal bone growth: a 7-year longitudinal study. J Bone Miner Res 2011;26: 2204-11.

40. Bonofiglio D, Garofalo C, Catalano S, Marsico S, Aquila S, Ando S. Low calcium intake is associated with decreased adrenal androgens and reduced bone age in premenarcheal girls in the last pubertal stages. J Bone Miner Metab 2004;22:64-70.

41. Vanderschueren D, Venken K, Ophoff J, Bouillon R, Boonen S. Clinical review: sex steroids and the periosteum-reconsidering the roles of 
androgens and estrogens in periosteal expansion. J Clin Endocrinol Metab 2006;91:378-82.

42. Kim BT, Mosekilde L, Duan Y, Zhang XZ, Tornvig L, Thomsen JS, et al. The structural and hormonal basis of sex differences in peak appendicular bone strength in rats. J Bone Miner Res 2003;18:150-5.

43. Prezelj J, Kocijancic A. Bone mineral density in hyperandrogenic amenorrhoea. Calcif Tissue Int 1993;52:422-4.

44. Sultan C, Paris F, Jeandel C, Attal G, Lumbroso S, Dumas R. L'Âge de la puberté et de la ménarche en France. Rev Int Pediatr 2001;32:9-10.

45. Kassanos D, Trakakis E, Baltas CS, Papakonstantinou O, Simeonidis G, Salamalekis $\mathrm{G}$, et al. Augmentation of cortical bone mineral density in women with polycystic ovary syndrome: a peripheral quantitative computed tomography (pQCT) study. Hum Reprod 2012;25:2107-14.

46. Beck TJ, Gayler BW. Image quality and radiation levels in videofluoroscopy for swallowing studies: a review. Dysphagia 1990;5:118-28.

47. Moghetti P, Castello R, Zamberlan N, Rossini M, Gatti D, Negri C, et al. Spironolactone, but not flutamide, administration prevents bone loss in hyperandrogenic women treated with gonadotropin-releasing hormone agonist. J Clin Endocrinol Metab 1999;84:1250-4.

48. Rosner W, Auchus RJ, Azziz R, Sluss PM, Raff H. Position statement: utility, limitations, and pitfalls in measuring testosterone: an Endocrine Society position statement. J Clin Endocrinol Metab 2007;92:405-13. 